\title{
An integrated surface water, groundwater and wetland plant model of drought response and recovery for environmental water management
}

\author{
$\underline{\text { P.D. Driver }}^{\text {a }}$, E.J. Barbour ${ }^{b}$ and K. Michener ${ }^{c}$ \\ ${ }^{a}$ NSW Office of Water and the Cooperative Research Centre for eWater, Australia; \\ ${ }^{b}$ Australian National University and the National Centre for Groundwater Research and Training, \\ Australia. \\ ${ }^{c}$ NSW Office of Water (NOW) and Queanbeyan City Council, NSW, Australia. \\ Email: patrick.driver@water.nsw.gov.au
}

\begin{abstract}
Modelling and associated reporting of ecosystem drought recovery across the Murray Darling Basin (MDB) is critical for managing inter-and intra-annual delivery of environmental flows. Such modelling and reporting can enable the provision of timely information during phases of critical decision making, especially when deciding which assets (locations) most need environmental water. To enable integrated (conjunctive) management of surface water and groundwater resources for environmental outcomes, such timely reporting of wetland response to drought cannot always rely on the availability of complex groundwater and surface water models because such models rely on detailed data, which is not always available.
\end{abstract}

We develop an autoregressive model of adjusted river flow versus plant biomass for two key sites within the Great Cumbung Swamp (GCS, Lachlan Valley, MDB). The model operates over drought and flood conditions, and incorporates previous flows (and hence antecedent conditions). The incorporation of both previous and current flows is used to represent change in wetland water volume ( local flood depth), which in turn is a key factor in influencing plant survival and growth. Cumbungi (Typha species; hereafter Typha) and Common Reed (Phragmites australis; hereafter Phragmites) are represented using a surrogate measure for wetland plant biomass. These wetland plant taxa represent local plant communities (dominating groundcover scores) at environmental flow monitoring sites. Phragmites is known to better utilise local, shallow groundwater and therefore we predicted that Phragmites would be more resilient and resistant to drought. The dependence of plants on both surface flows and groundwater is also explored, by examining changes in biomass during both moderate and dry periods, and the potential to access shallow groundwater (plant data was not available for a wet period). The models indicate the extent to which groundwater versus surface flows influence the observed localized, species-specific responses. We also explore local depthconductivity relationships to estimate the extent of groundwater loss or evaporative concentration, with the hypothesis that conductivity does not change. Previous models of groundwater loss for the GCS as-a-whole indicate that the GCS is a losing system, and hence does not concentrate solutes through evapotranspiration.

We found, as expected, that Phragmites abundance takes longer to fall during a drought and recovers more quickly; indicating an overall greater resistance and resilience to drought effects. However, during wetter periods this relationship breaks down, and presumably other factors (e.g., temperature) are the main determinants of plant growth. Also, and surprisingly, in spite of previous groundwater models and the probable high dependency of Phragmites on shallow groundwater during drought, there appears to be very little groundwater loss at monitoring sites. This, and previous studies on the generally impermeable clays within the GCS, indicates that the monitoring sites are operating as perched wetland systems. Phragmites is accessing groundwater that is not infiltrating locally within the study sites, or diffusely across the entire GCS, but instead is accessing groundwater recharged within numerous other locations across the GCS. We conclude that such models help inform management actions so that they can focus on species-specific water requirements, particularly under drought conditions. If such studies were widespread, then comparisons of these water availability-plant response dynamics among MDB wetlands could be used to draw further conclusions about the relative resilience of plant species and communities to drought.

Keywords: Wetlands, Drought, Resilience, Resistance, Groundwater 


\section{INTRODUCTION}

Reporting on ecosystem health under different hydrological scenarios in Australia often utilises simple outputs linked to river flow models, such as wetland commence-to-flows (Hameed and Podger 2001, Chessman et al. 2003, Driver et al. 2010). The lack of knowledge on ecological responses linked to drought effects within such models could hamper effective environmental flow delivery. Drought changes the priorities of ecological assets, depending on which assets are more dependent on maintenance (ecosystem survival) flows. In such instances, timely reporting of asset needs is necessary to assist in prioritising delivery. Such environmental flow models need to further integrate drought effects on ecosystems and species-specific responses to groundwater availability. Neither drought nor subsequent groundwater loss are usually well-reported. This paper explores flow-vegetation response relationships, including the effect of availability of groundwater under drought conditions within the GCS (Figure 1) by:

- Exploring wetland inflows versus the abundance of two locally dominant plant species with different flow requirements; Typha and Phragmites. We predicted that Phragmites would be more resilient and resistant to drought. Resilience and resistance are respectively the speed with which a community returns to its former state, and the ability to avoid displacement from a state (Begon et al. 1996); and

- Exploring local depth-conductivity relationships to find evidence of groundwater loss or evaporative concentration, with the hypothesis that conductivity does not change because of previously documented groundwater losses in the GCS as a whole (Driver et al. 2004).

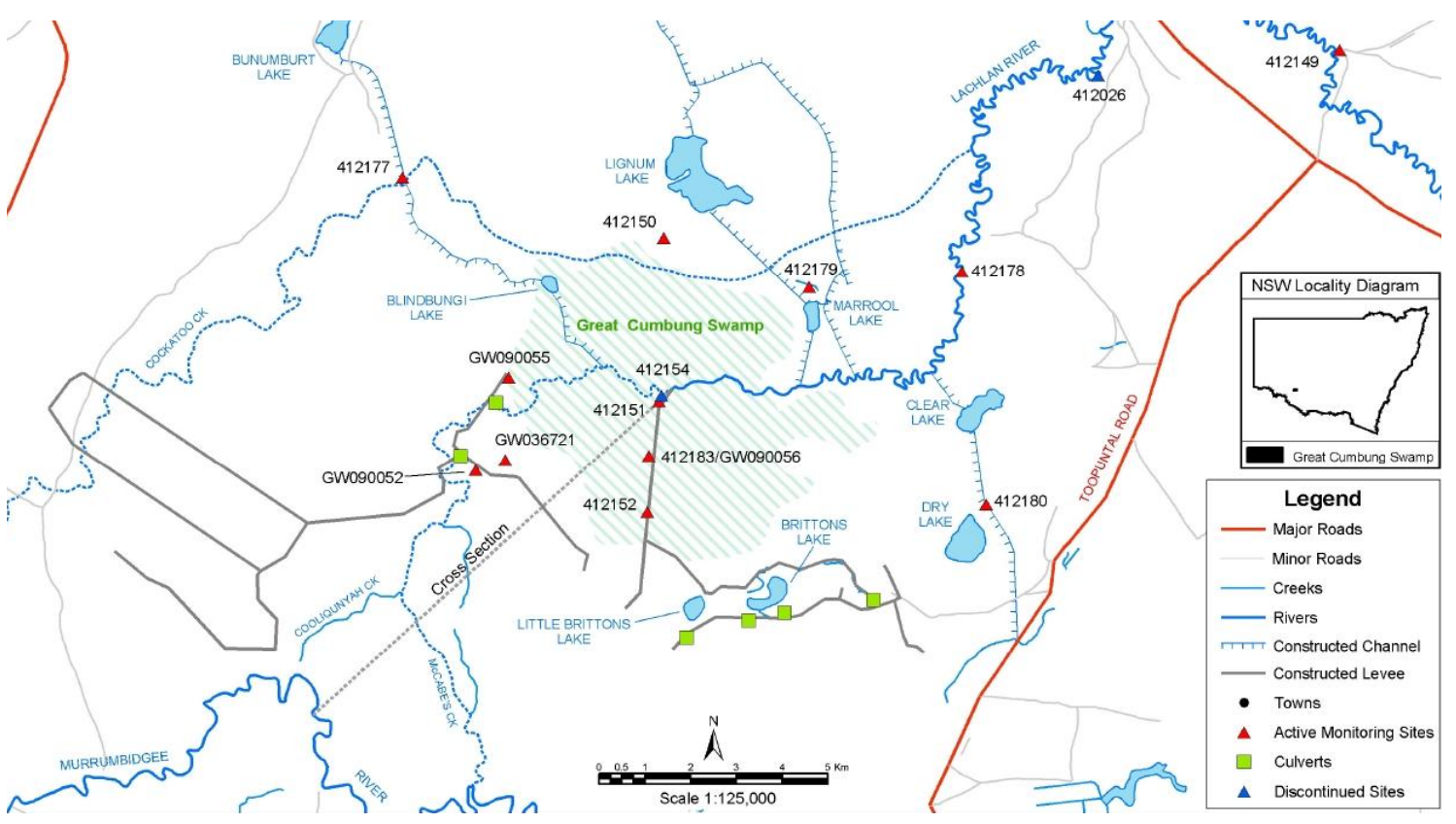

Figure 1. Schematic of gauging sites, roads, streams and floodplain structures in the GCS (Driver et al, 2004). Six digit codes shown are those used to designate NOW stream and ecological monitoring sites.

\section{STUDY AREA AND METHODS}

The study focuses on two sites, Lake Marrool and the Reed Bed (Figure 1). Phragmites dominates the Reed Bed (hashed area within Figure 1; site 412151). Lake Marrool is a backwater lake, which is dominated at its margins by Typha. Numerous factors affect plant growth such as salinity, temperature, nutrition and land management practices (e.g. Hocking et al. 1983). In this paper we focus on water availability. Phragmites is the deeper-rooted of the two species, utilising wet soils and groundwater to depths of 3-4 m (e.g. Kohzu et al. 2003). Phragmites is also less reliant on near-permanent surface water (Finlayson et al. 1983; Hocking et al. 1983). In the GCS, floodwater recharges a shallow aquifer system known as the Coonambidgil (Figure 2), 
and should be available to Phragmites in sites close to the river such as at the Reed Bed site.

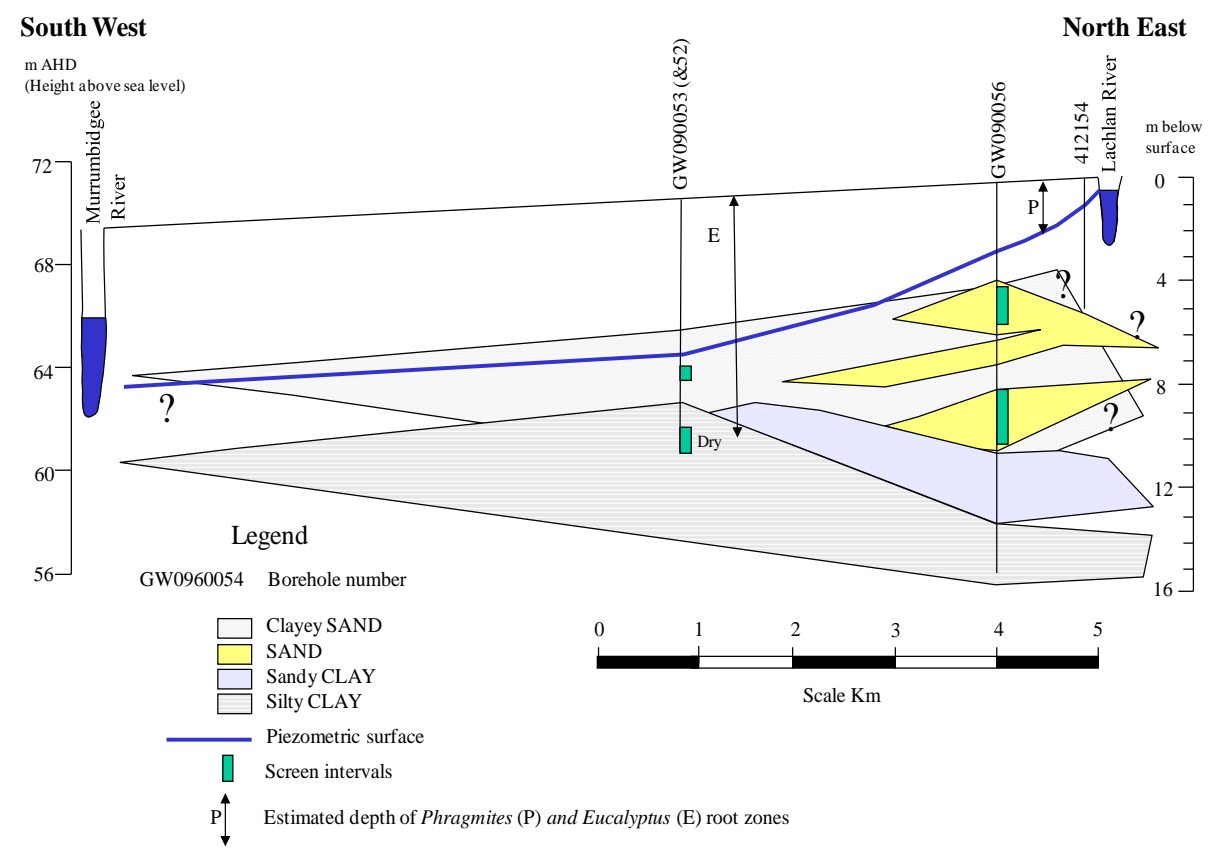

Figure 2. Schematic of surface water recharge of groundwater in the GCS (Driver et al. 2004). Alluvial aquifers (including the Coonambidgil formation) are shown. '?' indicates greater uncertainty in the extent and shape of a sand layer. The location of this cross section is shown is shown in Figure 1.

\subsection{Rivers inflows and the response of two wetland plant species}

Wetland plant response to water is largely dependent on the depth and duration of surface water inundation, as well as access to groundwater for deeper-rooted species. Given that surface water depth in a wetland is a function of both current and previous flows, a relationship was derived between wetland plant response and river flow taking into account previous flows. This was done using an autoregressive model, whilst plant response was represented using a biomass score.

\section{River flow representation}

An autoregressive model was used to adjust daily-observed river flows, to incorporate the effect of previous flows. The autoregressive model adjusts flows by incorporating only a percentage of the current observation as well as a percentage of preceding observations (also see Barbour et al., this congress):

$$
\Delta_{\mathrm{i}}=\mathrm{a} \Delta_{\mathrm{i}-1}+(1-\mathrm{a}) \mathrm{Q}_{\mathrm{i}}
$$

Equation (1)

Where:

$$
\begin{aligned}
& \Delta=\text { adjusted } \mathrm{Q}, \mathrm{i}=\text { time step, } \mathrm{a}=\mathrm{e}^{-1 / \tau} \\
& \mathrm{Q}=\text { flow }(\mathrm{ML} / \text { day }), \tau=\text { calibration parameter based on importance of previous flows }
\end{aligned}
$$

In equation 1 , the parameter $\tau$ was calibrated using observed plant biomass data (described below), by minimising the sum of the squared error between adjusted flow and biomass. The adjusted flow values are sensitive to the initial value at $i=0$, however, in this case approximately 52 years of data prior to the dates of interest were used to ensure values were not influenced by the initial flow. As the relationship is calibrated to biomass data for a specific species, the shape of this relationship also varies according to plant species, and river location. Flow data from Booligal River gauge ( $100 \mathrm{~km}$ upstream) was used to develop the autoregressive model; given it has the longest record period of those closest to the GCS.

\section{Flow- Plant response representation}

Having developed an adjusted flow time series as representative of the variation of depth within a wetland, the adjusted flow was then plotted against plant biomass for both moderate and dry periods. Biomass was calculated for Typha at Lake Marrool and Phragmites within the Reed Bed. Plant data was collected between 2000 and 2011; once before the flooding period and, if flooding, another survey at about three months after 
first fill in 2000 and 2001, and then with less regular, typically-event based monitoring (except in 2005) during the drought from 2002 to 2011 (March, November and December 2000, April, October and December 2001, January and April 2002, May 2003, December 2005, September 2008 and April 2011; N =12). Percentage groundcover was recorded in the field using the Braun-Blanquet scale (Chessman et al. 2003, Driver et al. 2003) and back-converted to percentage scores assuming a midpoint value for the range (e.g. 5$25=15 \%$ ). A biomass score was created using height and percentage cover measured in the field. This biomass score is not a direct measure of biomass, but is a representation of when plant biomass and volume was relatively lower or higher. This is a unit-free index ranging from 0-100 created from the product of percentage ground cover and average height (from 0-2 $\mathrm{m}$ ).

To investigate the likelihood of Phragmites accessing groundwater during drought, Phragmites biomass was plotted on the same graph as groundwater levels from two bores (GW090054 and GW090056). These bores were chosen given they were active during the time plant data had been collected; had the most observations of the data sets available for that time period; and accessed the shallow Coonambidgil aquifer.

\subsection{Local depth-conductivity relationships}

As a separate, but conceptually related modelling exercise the loss to groundwater within monitoring sites was explored by plotting conductivity versus water depth relationships. An increase in conductivity is suggestive of evaporation being the dominant loss, whereas a stable level may be indicative of loss to groundwater.

\section{RESULTS AND DISCUSSIONS}

\subsection{Rivers inflows and the response of two wetland plant species}

The autoregressive model was calibrated by minimising the difference between the adjusted flow (representative of depth) and observed plant biomass for both Typha at Lake Marrool $(\tau=250)$ and Phragmites at the Reed Bed $(\tau=260)$. Curve fitting was optimised by choosing models with the lowest standard error. Both of these values of $\tau$ indicate a high correlation between the current adjusted wetland storage and previous values, suggesting the importance of antecedent conditions in predicting plant response. Plant biomass was then plotted against adjusted wetland storage for both moderate and dry periods (Figure 3). Moderate and dry periods were taken to be the middle and lowest $33 \%$ of a probability flow duration curve for Booligal gauge respectively (where the flow curve was derived from the period of record from 1948 to 2009, adjusted for missing data using annual average flows). Given that plant data was collected from early 2000 to 2011, the moderate period covered 2000 to 2001 and the dry from 2002 to 2008.

Both plant species appear to be more dependent on flow during drought compared with wetter periods. During the dry period Typha continues to increase in abundance with adjusted flow after about 300 ML/day (Figure 3a), whereas Phragmites seems to respond immediately to flows up to about this value, and then show no further gain in biomass (Figure $3 b$ ). The observed patterns during the dry period reflect the expected lower drought tolerance of Typha, which needs sustained flood depths. An adjusted value of 350-400 $\mathrm{ML} /$ day reflects the minimum inflow that needs to be sustained in order to ensure surface flow and/or some shallow aquifer recharge into the GCS. In comparison, this study shows that Phragmites responds more quickly to flow, indicating it might benefit from smaller flows which - given the data was collected during drought - are unlikely to represent surface flows, but could enable the recharge of the shallow aquifer system. In both cases, these relationships could be used to estimate flow thresholds required to trigger plant response in the two study areas during dry periods. 

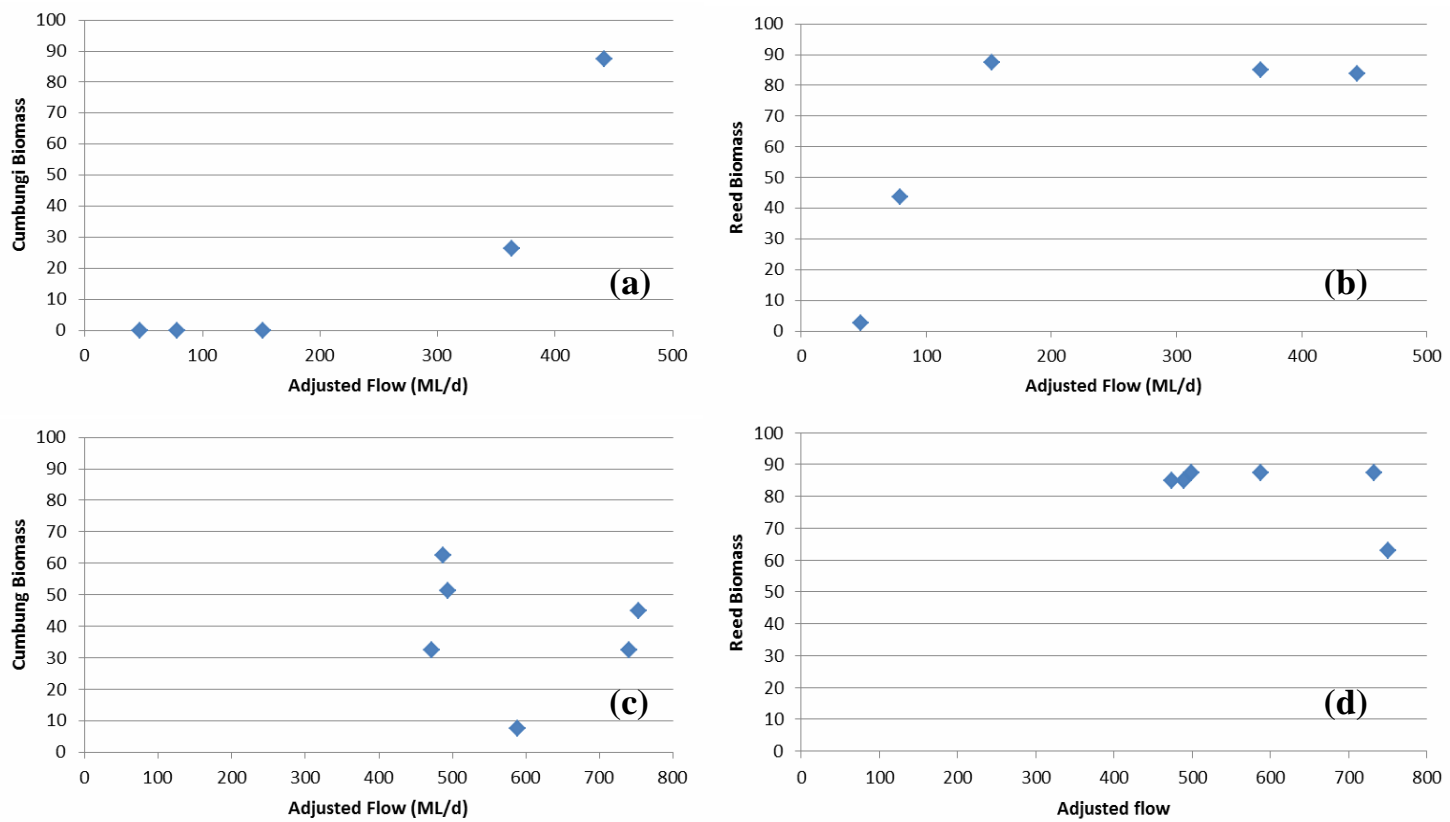

Figure 3. Change in plant biomass against adjusted flow showing (a) Cumbungi (Typha spp.) and (b) Common Reed (Phragmites australis) during a dry period; and (c) Cumbungi and

(d) Common Reed during a wet period.

The relationship between biomass and adjusted flow is less distinct during the moderate period, suggesting that during wetter conditions other factors (e.g. temperature) determine growth.

By plotting change in biomass over time (not adjusted flow) for both Typha and Phragmites, similar differences can also be observed between moderate and dry periods, as well as between species (Figure 4). Typha rapidly declines when surface water availability is reduced, whereas the decline in Phragmites biomass is more gradual. During the moderate period, there is high variability in biomass particularly for Typha, again suggesting that factors other than water availability are primarily affecting Typha growth.

The plots of Phragmites biomass in relation to groundwater data from bores (Figure 5) suggest some functional connection between these observations. The groundwater bores might not be representative of all groundwater levels across the Reed Bed, and hence levels could have been closer to the surface; but there are too few data points to know at this stage. It is also unlikely that the Phragmites is accessing groundwater at depths beyond three metres. Nonetheless, the data from GW90054 is consistent with the surface water data (which is known to drive the shallow groundwater mound), indicating that groundwater available to Phragmites dropped below this depth at the commencement of the drought.

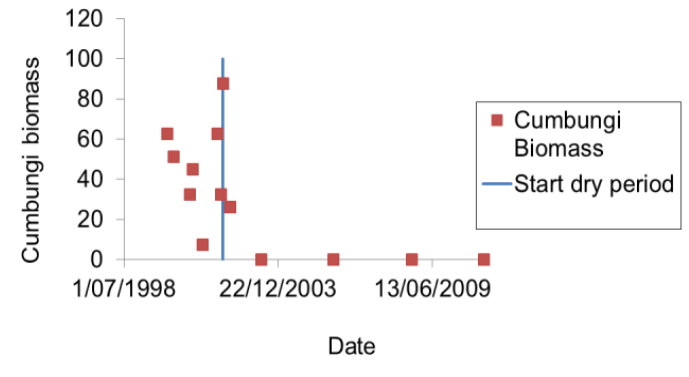

a

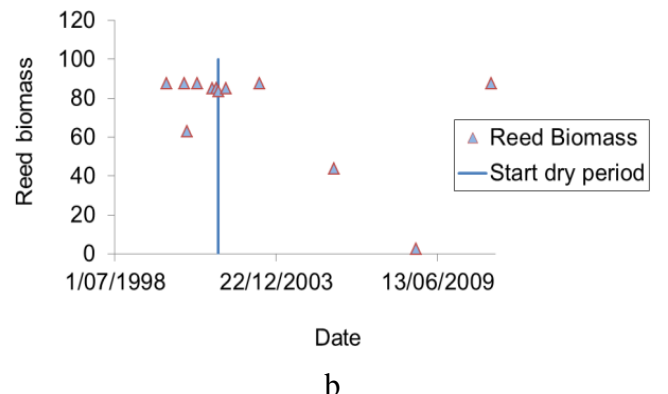

Figure 4. Loss and recovery of aquatic plants at the margin of (a) Cumbungi (Typha spp.) at Lake Marrool and (b)

Common Reed (Phragmites australis) within the reed bed, both within the Great Cumbung Swamp. 
Although the GCS as a whole is a groundwater losing system (Driver et al. 2004, 2010), at the sediment/soil surface within plant monitoring sites there appears to be minimal local infiltration into the groundwater. This is likely to be another reason why these plant species persist, as although water quality might deteriorate, water availability is maintained for shallow root systems. The water depth-conductivity plots clearly indicate evaporative concentration (Figure 6). This, and previous studies on the generally impermeable clays within the GCS (Driver et al. 2004), indicates that the deeper roots of Phragmites are accessing groundwater that is not infiltrating locally, but are accessing groundwater that often infiltrates at numerous small-scale locations. Groundwater infiltration is likely to occur at numerous locations such as within exposed palaeochannel sands along the eastern edge of Lake Bunumburt (Figure 1; PD, pers. obs.) and within numerous sinkholes often $<1 \mathrm{~m}$ in diameter. The role of sinkholes in aquifer recharge is well supported by anecdotal accounts by GCS landholders and direct post-drought observations of sinkhole activity within wetland monitoring sites during 2008-2011 (e.g., Lignum Lake, GCS in April 2011, PD, pers. obs., and within Mole Marsh, Macquarie Marshes; see Michener and Driver 2010).

\section{CONCLUSIONS}

This study highlights challenges in developing models to link ecological response to flow, including determining when flow is a key limitation in plant growth, or when other factors dominate. While our results are based on only a decade of observations they do suggest clear species-specific differences which are consistent with our understanding of their ecology. In particular, maintenance and monitoring of shallow groundwater and soil water systems is critical for deeper-rooted wetland species. Our models can be better tested locally with more data, and tested conceptually with work in other MDB wetland systems. Although more groundwater, surface water and plant data is required to approach certainty in how to manage these systems, the models we present provide sufficient information with which to target locations and species with a clearer understanding of groundwater and surface water needs. The methods we employ here also get the most value out of limited data and rapid field assessment methods; thereby enabling higher turnover of relevant information for water management and further development of associated decision-support tools (e.g. see Barbour et al., this congress).

The finding that, locally, conductivity-depth relationships do not indicate major groundwater loss, simply illustrates the complexity of the local effects of soil and groundwater, and the need to not be complacent about assumed wetland functions. It appears that, effectively, the wetland sites within the GCS are perched islands within a groundwater recharging system. If these islands did not exist, local loss of surface water to groundwater might deprive these plants of sufficient water over time. However, this finding might also signal ecosystem health risks, because if local surface water is concentrating solutes then there could be local salinity impacts on plants as a result (see Jolly et al. 2008). 
Studies on groundwater-surface water interactions in Australia are very few (Jolly et al. 2008). Hence, findings such as these help put observations elsewhere in the MDB in context. For example, losses have occurred in the abundance of common reed in parts of the Macquarie Marshes such as the Southern Nature Reserve (DECCW 2010); suggesting the level and duration of drying in the soil and/or shallow groundwater over previous decades must have been profound. That is, a combination of effects, particularly stream bed lowering (which lowers shallow aquifers), consumptive use of surface water and drought have been sustained for long enough to kill off the Phragmites root stock; as there was no recovery even in wetter years such as 2009/10 (see Brereton et al., 2000; Michener and Driver 2010). Hence, in the GCS, based on the dominant plant species, community resilience and resistance appears to be greater than in impacted wetland areas such as the Southern Nature Reserve. Within the GCS, Phragmites is more resilient and resistant to reduced water availability than Typha, and this study indicates this is because of greater use of shallow groundwater.

\section{ACKNOWLEDGEMENTS}

Thanks to government colleagues who collected and managed plant and flow data, notably Peter LloydJones, Michael Longhurst, Suzanne Merritt and Joseph Cairns. Martin O’Rourke (NOW) prepared Figure 2.

\section{REFERENCES}

Barbour, E., P.Driver, G. Kuczera, R. Blakers, and B. Croke (this congress). Optimising environmental flow rules - a conceptual model. In MODSIM 2011 International Congress on Modelling and Simulation, Modelling and Simulation Society of Australia and New Zealand.

Begon, M., J.L. Harper, and C.R. Townsend (1996). 'Ecology. Individuals, Populations and Communities. Third Edition'. (Blackwell Science: Oxford, England.)

Brereton, G., G. Steenbeeke, T. Witts, and R. Kidson (2000). A review of recent studies investigating biological \& physical processes in the Macquarie Marshes. Proceedings of the Macquarie Marshes Scientific Workshop 27-28 February 1996. NSW Department of Land and Water Conservation.

Chessman, C., E. Avery, C. Burton, P. Driver, S. Dwyer, T. Fulford, S. Grimes, I. Growns, L. Hardwick, D. Hohnberg, C. Howden, R. Kidson, P. Lloyd-Jones, J. Maguire, W. Mawhinney, L. Thurtell, S. Unthank, and D. Westhorpe (2003). Integrated monitoring of environmental flows. State summary report 19982000. NSW Dept of Infrastructure, Planning and Natural Resources.

DECCW (2010). Macquarie Marshes Adaptive Environmental Management Plan. Synthesis of information projects and actions. Department of Environment, Climate Change and Water NSW.

Driver, P.D., L. Hardwick, J. Maguire, and P. Lloyd-Jones (2003). Vegetation Survey for Billabongs. In Integrated Monitoring of Environmental Flows Methods Manual. Scientific and Technical Operating Procedures. Chessman, B. (ed.). New South Wales Department of Infrastructure, Planning and Natural Resources.

Driver, P., M. O’Rourke, M. Robinson, J. Jones, G. Raisin, and P. Wettin (2004). Great Cumbung Swamp Water Balance Assessment. NSW Department of Infrastructure, Planning and Natural Resources.

Driver, P.D., S. Chowdhury, T. Hameed, M. O’Rourke, and M. Shaikh (2010). Ecosystem response models for lower Calare (Lachlan River) floodplain wetlands: managing wetland biota and climate change modelling. In: Overton I, Saintilan N (eds.) Ecosystem response modelling in the Murray-Darling Basin, CSIRO Publishing, pp 183-196.

Finlayson, C.M., J. Roberts, A.J. Chick, and P.J.M. Sale (1983). The Biology of Australian Weeds II. Typha domingiensis Pers. and Typha orientalis Presl. The Journal of the Australian Institute of Agricultural Science, 49, 3-11.

Hameed, T., and G. Podger (2001). Use of IQQM simulation model for planning and management of a regulated river system. In: 'Integrated Water Resources Management. IAHS Publication no. 272'. (Eds. M A. Mariño and S. P. Simonovic) pp.83-89. International Association of Hydrological Sciences.

Hocking P.J. C.M. Finlayson, and A.J. Chick (1983). The Biology of Australian Weeds 12. Phragmites australis (Cav.) Trin. Ex Steud. The Journal of the Australian Institute of Agricultural Science, 49, 123132.

Jolly, I.D., K.L. McEwan, and K.L. Holland (2008). A review of groundwater-surface water interactions in $\mathrm{arid} / \mathrm{semi}$-arid wetlands and the consequences of salinity for wetland ecology. Ecohydrology, 1, 43-58.

Kohzu A., K. Matsui, T. Yamada, A. Sugimoto, and N. Fujita (2003). Significance of rooting depth in mire plants: Evidence from natural 15N abundance. Ecological Research 18, 261-270.

Michener, K. and P. Driver (2010). Vegetation responses to environmental flows in the Macquarie Marshes, 2009/2010. Water Resource Evaluation, NSW Office of Water. 